\title{
DIAGNOSTIC ACCURACY IN CASES OF ACUTE APPENDICITIS MODIFIED ALVARADO SCORE SYSTEM VS. ULTRASONOGRAPHIC IMAGING
}

\author{
Manisha Srivastava1, Brijendra Nigam², Saket Nigam³, Umesh Paliwal ${ }^{4}$ \\ ${ }^{1}$ Assistant Professor, Department of Surgery, Rama Medical College, Hospital and Research Centre, Kanpur. \\ ${ }^{2}$ Assistant Professor, Department of Surgery, Rama Medical College, Hospital and Research Centre, Kanpur. \\ 3 Assistant Professor, Department of Radiodiagnosis, Rama Medical College, Hospital and Research Centre, Kanpur. \\ ${ }^{4}$ Associate Professor, Department of Pathology, Rama Medical College, Hospital and Research Centre, Kanpur.
}

\section{ABSTRACT}

\section{OBJECTIVE}

To compare preoperative diagnostic accuracy in cases of Acute Appendicitis with Modified Alvarado Scoring as compared to diagnostic ultrasonographic imaging.

\section{DESIGN}

Cross sectional study.

\section{SETTING AND DURATION}

Surgical Unit-I of Rama Medical College Hospital and Research Centre, Kanpur, from 1st March 2013 to 31 st May 2015.

\section{METHODOLOGY}

After ethical approval of ethics committee, Rama Medical College Hospital and Research Centre, a sample of 150 patients was collected by non-probability purposive sampling technique during 26 months, who were admitted in this hospital and included in this study and later underwent abdominal ultrasonography and appendectomy and subsequently pathological evaluation of the appendix done for disease appendicitis. Results of outcome of histopathology compared with MASS and ultrasonography results. Patients underwent appendectomy were assessed by senior consultants of the Surgical Department for exclusion of patients with complication of appendicitis and other causes of lower abdominal pain. Modified Alvarado Score System (MASS) was recorded preoperatively, but its result was not disclosed to effect the decision of surgery. After appendectomy, the appendix was sent for histopathology which was taken as gold standard or confirmation of disease. The results of histopathology compared with ultrasonographic imaging diagnosis and Modified Alvarado Scoring System to assess the diagnostic accuracy of both modalities.

\section{RESULTS}

110 males and 40 female patients were assessed. Of these patients, 134 (89.3\%) had histopathology positive acute appendicitis. The sensitivity, specificity, PPV, NPV and accuracy rate of ultrasonography was found 77.6\%, 75.0\%, 96.2\%, 28.7\% and 77.3\%, respectively. By taking a cut-off point of 7 for the MASS score, a sensitivity of $65.67 \%$, specificity of $37.5 \%$, PPV of $89.79 \%$, NPV of $11.5 \%$ and accuracy of $62.6 \%$ were calculated.

\section{CONCLUSION}

Ultrasonography provides more reliable information for helping to diagnose acute appendicitis. A cut-off point of 7 for the MASS score has less sensitivity and accuracy as compared to clinical diagnosis assisted with ultrasonography for better diagnosis of appendicitis and to decrease the rate of negative appendectomy.

\section{KEYWORDS}

Acute Appendicitis, Appendectomy, Ultrasonography, Modified Alvarado Scoring System (MASS).

HOW TO CITE THIS ARTICLE: Srivastava M, Nigam B, Nigam S, et al. Diagnostic accuracy in cases of acute appendicitis modified Alvarado score system vs. ultrasonographic imaging. J. Evolution Med. Dent. Sci. 2016;5(34):1899-1902,

DOI: $10.14260 /$ jemds/2016/449

\section{INTRODUCTION}

Acute Appendicitis is the most common cause of acute abdominal pain and appendectomy is the most frequently performed emergency surgery in the world. ${ }^{1}$ with lifetime occurrence of $7 \%$. The peak incidence occurs between 10-30 years of age; however, no age is spared. ${ }^{2}$ Approximately, $6 \%$ of the population will suffer from acute appendicitis during their lifetime. ${ }^{3}$

Financial or Other, Competing Interest: None.

Submission 03-03-2016, Peer Review 04-04-2016,

Acceptance 11-04-2016, Published 27-04-2016.

Corresponding Author:

Dr. Manisha Srivastava

\#13, Hemant Vihar Sector 3,

Barra 2, Kanpur-208027,

Uttar Pradesh.

E-mail: brijendramanisha@yahoo.com

DOI: $10.14260 /$ jemds/2016/449
Although, acute appendicitis has been recognized as a clinical entity for 100 years, the differential diagnosis between acute appendicitis and non-specific abdominal pain may still be exigent. Early diagnosis and prompt operative intervention is the key for successful management of acute appendicitis. ${ }^{4}$

So many appendicectomies are performed for nonappendiceal pathologies, so-called unnecessary or negative appendectomies because of similarities in the clinical presentation, especially in young women. ${ }^{5}$ On the other hand, there remains always a possibility of complications in effort to decrease the negative appendectomy rate. Traditionally, most favoured and most effective way to decrease rate of perforation is to have a lower threshold for operating at the expense of increasing negative appendicectomy rate. 6 From the beginning of abdominal complaints to admission in a hospital, delays of few hours to a few days may occur. 
Accurate and prompt diagnosis reduces the risk of perforation and negative appendectomy rate. ${ }^{7}$ Although in acute appendicitis mortality is low, morbidity remains high. Immediate appendectomy has long been recommended treatment of appendicitis, because of the known risk of progression to complications. Rate of appendiceal perforation increases from less than $2 \%$ when appendectomy is performed within 36 hours of symptom onset to $5 \%$ after this time period. ${ }^{8}$ Diagnosis of acute appendicitis is established primarily on patient's history and physical examination supported by laboratory and imaging examination. Delay in diagnosis and treatment is by far the main cause of appendiceal perforation. ${ }^{9}$

Despite many advances in diagnostic system, acute appendicitis is still a diagnostic dilemma at times and challenge too. ${ }^{10} \mathrm{An}$ accurate diagnosis can only be obtained at surgery or after histopathological examination of surgical specimen. ${ }^{11}$ Accurate identification of patients who require immediate surgery as opposed to those who will benefit from active observation is not always easy. ${ }^{12}$ Several authors have created diagnostic scoring systems in which a finite number of clinical variables are elicited from the patients and each one is given a numerical value. The sum of these values has been used to predict the likelihood of acute appendicitis.

Clinical scoring systems for adults have been developed to increase the diagnostic accuracy and decrease the unnecessary appendectomy rate. ${ }^{13}$ Some developers of the diagnostic scores have suggested a decrease of unnecessary appendectomy rate of up to $50 \% \cdot{ }^{14,15}$ Scoring system such as Madan score, Ohmann score, Eskelinen score, DeDombal score, Francois Score and Alvarado score has been devised to aid diagnosis of acute appendicitis. ${ }^{16}$ Apart from scoring systems number of other diagnostic modalities have also been proposed including laparoscopy, computer programs, ultrasonography, CT scans and MRI. Imaging techniques are fairly accurate. ${ }^{17,18,19}$

Graded compression ultrasonography is an inexpensive, fast and non-invasive method with an accuracy rate of 71\%$90 \%$ for the diagnosis of acute appendicitis. But there is no certainty about the effect of ultrasonography on the clinical outcomes of patients. Furthermore, clinical judgment should not be abandoned because of the lack of ultrasound findings in patients with a high probability of acute appendicitis. Also, ultrasonography is an operator-dependent modality and the diagnostic values are different in various studies. ${ }^{20}$

The likelihood of appendicitis is ascertained by the Alvarado Scoring System. It is accepted that according to the Alvarado Scoring System which consists of right lower quadrant tenderness, rebound tenderness, migrating pain, nausea and/or vomiting, anorexia, fever, leucocytosis and a left shift in the leukocyte count. Patients who get a score of 7 to 10 should undergo appendectomy and patients with a score of 5 or 6 are candidates for observation. Modified Alvarado Scoring System (MASS) was developed by omitting the left shift of leucocytosis from the Alvarado Scale to make it more clinical and not lab dependent.21,22

Most hospitals do not count the neutrophils and also the CT scans are not available; therefore, we decided to evaluate the diagnostic value of the Modified Alvarado Scoring System (MASS) and the accuracy of graded compression ultrasonography in our setting for the diagnosis of acute appendicitis, comparing it with the gold standard of eventual histopathology in order to consider sensitivity, specificity, NPV (Negative Predictive Value), PPV (Positive Predictive Value) and accuracy of MASS score as compared to the sensitivity, specificity, NPV, PPV and accuracy of ultrasonography assisted diagnosis of appendicitis in our medical college.

\section{METHODS}

This prospective observational study was conducted at Surgical Unit-I of Rama Medical College Hospital and Research Centre, Kanpur, from $1^{\text {st }}$ March 2013 to 31 3 st May 2015. All patients $>12$ years of age of either sex, clinically diagnosed as having acute appendicitis were enrolled. Alvarado score was also scored, but not accounted in decision making. All patients subjected to preoperative ultrasonography, a formal informed consent was duly taken. Patients with appendicular mass, appendicular abscess and those found to have perforated appendix at surgery were excluded.

Similarly, patients found to have obvious pathology other than or in addition to an inflamed appendix (e.g. rightsided ovarian cyst, inflamed Meckel's diverticulum, etc.) were not included. After standard pre-operative optimizations, the subjects underwent appendicectomy through a right grid-iron incision centered at the McBurney's point. The specimen was appropriately labelled and sent for histopathology. All specimens were sent to a Medical College Pathology Dept.

With a pre-defined protocol for pathological diagnosis of acute appendicitis (Two essential criteria: Subserosal congestion and neutrophil exudation in mucosa, submucosa and muscularis; two supportive criteria: foci of suppurative necrosis and those of gangrene). Patients with uneventful post-operative course were discharged after 36-48 hours of surgery; those with some morbidity were retained longer, depending on the nature of complication and its management.

All patients were called for follow-up in the outpatient, a week after the discharge with the biopsy report. All data were entered on a predesigned proforma including patient's demographic features (Age and gender), Modified Alvarado score, histopathological findings (Normal or inflamed appendix as per pre-set criteria enumerated above) and preoperative ultrasonographic report (Based on prefixed criteria of graded compression method and $>$ than 6 inch noncompressible intestinal loop) and final outcome, i.e. negative appendicectomy. In order to minimize any bias in favour of or against the hypothesis, Modified Alvarado scores were entirely calculated by senior residents who were not privy to the research.

\section{RESULTS AND DISCUSSION}

\section{Demographic Results}

One hundred ten (110) males and forty (40) females were assessed. The mean age of the patients was 27.97 years $(9$ to 84 years old). Although the average age seemed to be higher in the female group (30 years in comparison with 25.9 years in males), the difference was not significant ( $p$ value $>0.05$ ).

\section{Pathology Results}

Acute appendicitis was confirmed in $134(89.3 \%)$ of the patients and the remaining $16(10.7 \%)$ patients had undergone negative appendectomies.

\begin{tabular}{|c|c|}
\hline Characteristics & Frequency $(\mathbf{n = 1 5 0})$ \\
\hline Age (mean \pm SD) & $27.97+11.56$ years \\
\hline Gender (male/female) & $110 / 40$ \\
\hline \multicolumn{2}{|c|}{ Table 1: Patient Characteristics } \\
\hline
\end{tabular}




\begin{tabular}{|c|c|c|c|}
\hline & Female & Male & Total \% \\
\hline Appendicitis & 32 & 102 & $134(89.3 \%)$ \\
\hline Normal appendix & 8 & 8 & $16(10.7 \%)$ \\
\hline Total & $\mathbf{4 0}$ & $\mathbf{1 1 0}$ & $\mathbf{1 5 0}$ \\
\hline \multicolumn{4}{|c|}{ Table 2: Pathology Results } \\
\hline
\end{tabular}

\section{Ultrasound Results}

Ultrasonography was performed on all 110 male patients and 40 females.

\begin{tabular}{|c|c|c|c|}
\hline & $\begin{array}{c}\text { Appendicitis in } \\
\text { Ultrasonograph } \\
\mathbf{y}\end{array}$ & $\begin{array}{c}\text { Normal } \\
\text { Ultrasonograph } \\
\mathbf{y}\end{array}$ & $\begin{array}{c}\text { Tota } \\
\mathbf{l}\end{array}$ \\
\hline $\begin{array}{c}\text { Appendiciti } \\
\text { s }\end{array}$ & 108 & 26 & 134 \\
\hline $\begin{array}{c}\text { Normal } \\
\text { Appendiciti } \\
\text { s }\end{array}$ & 4 & 12 & 16 \\
\hline Total & $\mathbf{1 1 2}$ & $\mathbf{3 8}$ & $\mathbf{1 5 0}$ \\
\hline \multicolumn{3}{|c|}{ Table 3: Ultrasonographic Data } \\
\hline
\end{tabular}

The sensitivity for diagnosing acute appendicitis by ultrasound was $77.6 \%$, the specificity was $75.0 \%$ and the accuracy rate was $77.3 \%$. The Positive Predictive Value (PPV) for ultrasonography was $96.2 \%$ and the Negative Predictive Value (NPV) was $28.7 \%$ in our study.

\section{Modified Alvarado Score System results (MASS)}

MASS scoring was assessed in all 150 patients taking cut off as 7 .

\begin{tabular}{|c|c|c|c|}
\hline & Mass $>\mathbf{7}$ & Mass $<\mathbf{7}$ & Total \\
\hline Appendicitis & 98 & 36 & 134 \\
\hline Normal Appendicitis & 10 & 6 & 16 \\
\hline Total & $\mathbf{1 0 2}$ & $\mathbf{4 2}$ & $\mathbf{1 5 0}$ \\
\hline \multicolumn{4}{|c}{ Table 4: Mass Results } \\
\hline
\end{tabular}

The sensitivity for diagnosing acute appendicitis by MASS was $65.67 \%$, the specificity was $37.5 \%$ and the accuracy rate was $62.6 .4 \%$. The Positive Predictive Value (PPV) for MASS was $89.79 \%$ and the Negative Predictive Value (NPV) was $11.5 \%$ in our study. Among the MASS components, right lower quadrant tenderness was the most common and nausea and/or vomiting was significantly related with acute appendicitis ( $\mathrm{p}$ value 0.001 ).

\begin{tabular}{|c|c|c|}
\hline Manifestations & Value & $\%$ \\
\hline Migration of pain & 1 & 85.3 \\
\hline Symptoms Anorexia & 1 & 84.8 \\
\hline Nausea and/or vomiting & 1 & 68.8 \\
\hline \multicolumn{3}{|l|}{ Signs } \\
\hline Right lower quadrant tenderness & 2 & 88.3 \\
\hline Rebound & 1 & 87 \\
\hline Elevated temperature & 1 & 81.8 \\
\hline \multicolumn{3}{|l|}{ Laboratory Values } \\
\hline Leukocytosis $>11000 / \mathrm{mm}^{3}$ & 2 & 90.9 \\
\hline Total Score & 9 & \\
\hline \multicolumn{3}{|c|}{ Table 5: Modified Alvarado Scale Findings } \\
\hline
\end{tabular}

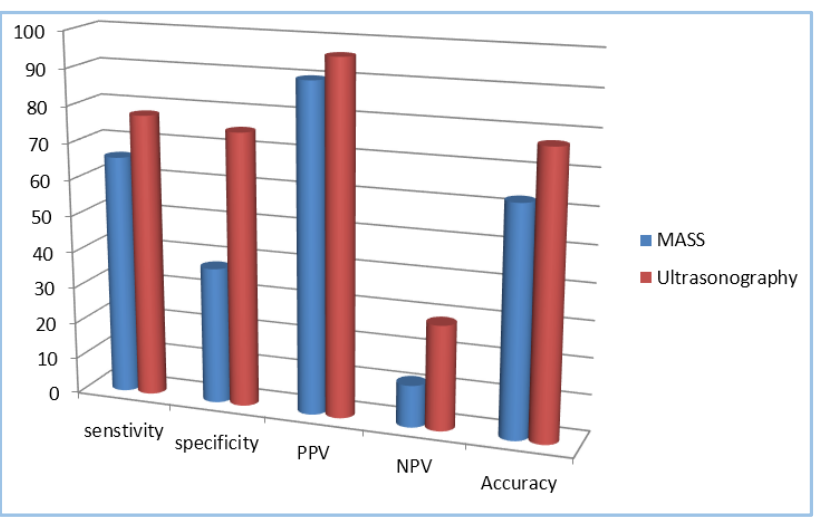

Fig. 1: Comparison of Results of Predictive Values of Ultrasonography versus MASS Scoring in Patients of Acute Appendicitis

\section{DISCUSSION}

This study was conducted to assess the predictive value of ultrasonography and MASS scoring systems to assist and improve the diagnosis of acute appendicitis. Ultrasonography is an affordable, non-invasive tool whose result can be obtained more quickly. Ultrasound has already been proved to have a high sensitivity and specificity in the diagnosis of acute appendicitis. Many data about this are available and 55\% to $98 \%$ sensitivity and $78 \%$ to $100 \%$ specificity have been reported for ultrasonography. Variations in reported data may be due to differences in study design, sample size, physician experience or applied statistical techniques of various studies. Ultrasound is an operator-dependent technique and the results vary depending on who is performing the ultrasonography.

In our study ultrasound had $77.6 \%$ sensitivity, $75.0 \%$ specificity and $77.3 \%$ accuracy. Comparing this study with others reveal that ultrasound provides reliable findings for the diagnosis of acute, even though it is done by radiology residents without much experience. The PPV of ultrasonography was $96.2 \%$ and the NPV was $28.7 \%$. These results emphasize again that a positive ultrasonography for appendicitis is strongly in favour of a diagnosis of acute appendicitis. However, a negative ultrasound is not sufficient to rule out the diagnosis and discharge the patient.

The Modified Alvarado Scoring System is based on signs, symptoms and laboratory data. It is a very sensitive tool for classifying patients with suspected acute appendicitis. Making it more clinical oriented, the Modified Alvarado Scoring System (MASS), omitting the neutrophil count, has been used as a clinical predictor of acute appendicitis diagnosis. In our study, MASS had $65.67 \%$ sensitivity, $37.5 \%$ specificity and $62.6 \%$ accuracy.

The PPV of MASS was $89.79 \%$ and the NPV was $11.5 \%$ comparing this study with ultrasonography reveals that ultrasound provides reliable findings for the diagnosis of acute as compared to MASS, even though it is done by radiology residents without much experience. The MASS has been shown to be a quick and inexpensive diagnostic tool in patients suspected of suffering acute appendicitis in clinical settings. However, different accuracies have been reported for the MASS in different studies. 


\section{CONCLUSION}

Decision-making in patients suspected of having acute appendicitis is still a diagnostic challenge worldwide despite the advances in appendiceal surgery and the decrease in mortality because of appendicitis. According to some articles, negative appendectomy has been reported in $15 \%$ to $30 \%$ of appendectomies, because of difficulties in making the diagnosis. This can impose a significance burden on the health system.

Ultrasonography and Modified Alvarado Score are both beneficial in diagnosis of acute appendicitis. Though Ultrasonography is operator dependent, it has reasonable sensitivity and specificity in diagnosis and superior diagnostic tool as compared to MASS scoring.

\section{REFERENCES}

1. Gulzar S, Umar S, Dar GM, et al. Acute appendicitis: importance of clinical examination in making a confident diagnosis. Pak J Med Sci 2005;21(2):125-32.

2. Hardin DM. Acute appendicitis: review and update. Am Fam Physician 1999;60(7):2027-34.

3. Gökçe AH, Aren A, Gökçe FS, et al. Reliability of ultrasonography for diagnosing acute appendicitis. Ulus Travma Acil Cerrahi Derg 2011;17(1):19-22.

4. Flum DR, McClure TD, Morris A, et al. Misdiagnosis of appendicitis and the use of diagnostic imaging. J Am Coll Surg 2005;201(6):933-9.

5. Ditillo MF, Dziura JP, Rabinovici R. Is it safe to delay appendicectomy in adults with acute appendicitis? Ann Surg 2006;244(5):656-60.

6. Marudanayagam R, Williams GT, Raees BI. Review of the pathological results of 2660 appendicectomy specimens. J Gastroenterol 2006;41(8):745-9.

7. Singhal R, Angmo N, Somaiah N, et al. A retrospective review of the histopathology and clinicopathologic correlates of appendices removed from patients of acute appendicitis. Minnerva Chir 2007;62(1):11-8.

8. Chavda SK, Hassan S, Magoha GA. Appendicitis at kenyatt a hospital, nairobi. East Afr Med J 2005;82(10):526-30.

9. Aslam M, Shaukat A, Zafar F, et al. Incidence of negative appendicectomy, our experience of 100 patients at sir ganga ram hospital lahore. Ann King Edward Med Coll 2005;11:461-2.
10. Alvarado A. A practical score for the early diagnosis of acute appendicitis. Ann Emerg Med 1986;15(5):557-64.

11. Kalan M, Talbot D, Cunliff E WJ, et al. Evaluation of the modified alvarado score in the diagnosis of acute appendicitis: a prospective study. Ann R Coll Surg Engl 1994;76(6):418-9.

12. Leung T, Dixon E, Gill M, et al. Bowel obstruction following appendectomy: what is the true incidence? Ann Surg 2009;250(1):51-3.

13. Teicher I, Landa B, Cohen M, et al. Scoring system to aid inthe diagnosis of appendicitis. Ann Surg 1983;198(6):753-9.

14. Lee SL, Walsh AJ, Ho HS. Computed tomography and ultrasonography do not improve and may delay the diagnosis and treatment of acute appendicitis. Arch Surg 2001;136(5):556-62.

15. Terasawa T, Blackmore CC, Bent S, et al. Systematic review: computed tomography and ultrasonography to detect acute appendicitis in adults and adolescents. Ann Intern Med 2004;141(7):537-46.

16. Horzic M, Salamon A, Koplijar M, et al. Analysis of scores in diagnosis of acute appendicitis in women. Coll Anropol 2005;29(1):133-8.

17. Stoker J, van Randen A, Laméris W, Boermeester MA: Imaging patients with acute abdominal pain. Radiology 2009;253(1):31-46.

18. Olsen JB, Myren CJ, Haahr PE. Randomized study of the value of laparoscopy before appendicectomy. Br J Surg 1993;80(7):922-3.

19. Moberg AC, Ahlberg G, Leijonmarck CE, et al. Diagnostic laparoscopy in 1043 patients with suspected appendicitis. Eur J Surg 1998;164(11):833-40.

20. Puylaert JB. Acute appendicitis: US evaluation using graded compression. Radiology 1986;158(2):355-60.

21. Denizbasi A, Unluer EE. The role of the emergency medicine resident using the alvarado score in the diagnosis of acute appendicitis compared with the general surgery resident. Eur J Emerg Med 2003;10(4):296-301.

22. Macklin CP, Radcliffe GS, Merei JM, et al. A prospective evaluation of the modified alvarado score for acute appendicitis in children. Ann RColl Surg Engl 1997;79(3):203-5. 